\title{
Osteopontin Promotes Bone Destruction in Periapical Periodontitis by Activating the NF-kB Pathway
}

\author{
Ming Dong ${ }^{\mathrm{a}} \quad$ Xinxin Yu ${ }^{\mathrm{a}} \quad$ Wanfang Chen $^{\mathrm{a}} \quad$ Zhenzhen Guo ${ }^{\mathrm{a}} \quad$ Linlin Sui ${ }^{\mathrm{a}}$ \\ Yuefei Xu ${ }^{a}$ Yuhong Shang ${ }^{b}$ Weidong Niuc Ying Konga \\ ${ }^{a}$ College of Basic Medical Sciences, Dalian Medical University, Dalian, ${ }^{\mathrm{b} D e p a r t m e n t}$ of Obstetrics \\ and Gynecology of Renal Disease, the First Affiliated Hospital of Dalian Medical University, Dalian, \\ 'Department of Endodontics and Periodontics, Dalian Medical University, Dalian, China
}

\section{Key Words}

Osteopontin • Bone absorption • Periapical periodontitis $•$ NF- $\mathrm{kB}$

\begin{abstract}
Background/Aims: Periapical periodontitis is caused by bacterial infection and results in both bone destruction and tooth loss. Osteopontin (OPN) is a secreted phosphorylated glycoprotein that participates in bone metabolism. Methods: Thirty-three patients with chronic periapical periodontitis and 10 patients who had undergone the orthodontic removal of healthy tooth tissue (control) at the periodontal ligament were investigated, and an animal model of mouse periapical periodontitis was established for an in vivo analysis. The relationship between OPN and bone destruction during periapical periodontitis was analyzed. Osteoblasts and osteoclasts were cultured in vitro and treated with lipopolysaccharide. An inhibitor of NF-KB was used to pretreat the transfected cells. Results: OPN increased osteoclast proliferation and differentiation, but reduced osteoblasts proliferation and differentiation. OPN activated the NF$\mathrm{KB}$ pathway during periapical periodontitis and accelerated the transfer and phosphorylation of P65 from the cytoplasm to the nucleus. Conclusion: This study demonstrated that OPN played important roles in the progression of periapical periodontitis, and a dual role in bone metabolism during periapical periodontitis, linking osteoclasts and osteoblasts. The underlying mechanism may be related to the NF-KB pathway.

(C) 2018 The Author(s)

Published by S. Karger AG, Basel
\end{abstract}

\section{Introduction}

Periapical periodontitis is caused by pulpal infection. The major clinical manifestation of periapical periodontitis is the destruction of the apical alveolar bone [1]. Bacterial lipopolysaccharide (LPS) is the main cause of periapical periodontitis because it stimulates the body's local immune response. A large number of inflammatory cells are activated after the release of inflammatory mediators, cytokines and enzymes, leading to the destruction of the apical tissue, the formation of inflammatory granulation tissue, and alveolar bone

M. Dong and X. Yu contributed equally to this work.

\begin{tabular}{ll}
\hline Dr. Ying Kong & College of Basic Medical Sciences, Dalian Medical University Dalian 116044, Liaoning; \\
and Weidong Niu & Department of Endodontics and Periodontics, Dalian Medical University, Dalian 116044, Liaoning (China) \\
& Tel. +8641186110312, E-Mail yingkong@dmu.edu.cn; niu.wd.endo@dmu.edu.cn
\end{tabular}




\section{Cellular Physiology Cell Physiol Biochem 2018:49:884-898 and Biochemistry Published online: 5 September, 2018 www.karger.com/cpb 2018 The Author(s). Published by S. Karger AG, Basel \\ Dong et al.: Osteopontin Promotes Bone Destruction in Periapical Periodontitis}

destruction [2-4]. The dynamic balance between osteoblasts and osteoclasts is the critical link in the process of periapical bone remodeling [5]. OPN is a secretory glycosylated extracellular matrix protein with many biological activities. It is a multifunctional matrix protein that is widely involved in the progression of bone-related diseases [6]. A number of studies have shown that OPN promotes osteoclast adhesion and improves the osteocytes activity of osteoclasts. When the $O P N$ gene was knocked out, the number of osteoclasts decreased significantly $[7,8]$.

Many studies have examined the role of cytokines in pathogenesis at the periapical circumference $[9,10]$, but there has been little research into the role of OPN in periapical periodontitis. In the present study, we investigated the function of OPN and analyzed the relationship between OPN and chronic periapical periodontitis. We provide evidence that $\mathrm{OPN}$ is involved in the pathogenesis of this disease.

\section{Materials and Methods}

\section{Tissue samples}

Thirty-three patients with chronic periapical periodontitis and 10 patients, who had undergone the orthodontic removal of healthy tooth tissue at the periodontal ligament (controls), at the Dental Hospital of Dalian Medical University between June 2016 and March 2017, were enrolled in the study. Informed consent was obtained from all the patients. The clinical subjects were divided into three groups. The samples from the first group were used to detect periapical-periodontitis-associated genes expressions; the samples from the second and third groups were used to detect periapical-periodontitis-associated protein expression with western blotting and immunohistochemistry, respectively. The subject inclusion criteria were: (1) the patient was in good health, with no systemic or periodontal disease; (2) the patient had taken no antibiotic or nonsteroidal anti-inflammatory drug within the preceding month; (3) on a dental examination, the teeth showed no pulp vitality, and the patient had undergone no pulp treatment and had no obvious percussive or spontaneous pain; (4) X-rays showed a slight shadow on the root, of about $2.5 \times 2.5 \mathrm{~mm}^{2}$; (5) the teeth required removal after the clinical diagnosis; and (6) the teeth showed periapical lesions.

\section{Real-time PCR}

The samples were added to Trizol Reagent (Trizol RNA Extractor, Sanggon Biotech, Shanghai, China) to extract the total RNA. The reverse transcription (RT) reaction was performed in a volume of $20 \mu \mathrm{L}$, with the PrimeScript RT Reagent Kit with gDNA Eraser (TaKaRa, Dalian, China), according to the manufacturer's instructions. The total real-time PCR volume was $25 \mu \mathrm{L}$, prepared according to the instructions for the TaKaRa SYBR $®$ Premix Ex Taq ${ }^{\text {TM }}$ II kit (TaKaRa). Real-time quantitative PCR was used to detect the target genes with specific primers: OPN, 5'-GGTGATGTCCTCGTCTGTAGCA-3' and 5'-GATGAATCTGATGAACTGGTCACT -3'; NF- $\kappa B, \quad$ 5'-TGTCAGAGCCCTTGTAACTG-3' and 5'-CTGTGGGTAGGATTTCTTGT-3'; MMP9, 5'-GCTTTCGGCTGCAGCTCTGCTG-3' and 5'-GAGGCCTTTGAAGGTTTGGAAT-3'; cathepsin $K$, 5'-CTGAGAATGTGGCTGTGGAG-3' and 5'-TACCCTCTGCATTTAGCTGCC-3'; and glyceraldehyde 3-phosphate dehydrogenase $(G A P D H)$, 5'-GTATCGGACGCCTGGTTA-3' and 5'-CATTTGATGTTAGCGGGAT-3'. The data were analyzed with the $2^{-\Delta \Delta C \mathrm{t}}$ method. Each real-time PCR contained $12.5 \mu \mathrm{L}$ of SYBR® Premix Ex Taq ${ }^{\mathrm{TM}}$ II (TaKaRa), $2 \mu \mathrm{L}$ of primer mix, $1 \mu \mathrm{L}$ of cDNA, and $9.5 \mu \mathrm{L}$ of deionized water in a final total volume of $20 \mu \mathrm{L}$. All PCRs were performed for 40 cycles and were run in triplicate.

\section{Western blotting}

Equal amounts of protein extracts $(50 \mu \mathrm{g})$ were separated with $12 \%$ sodium dodecyl sulfate -polyacrylamide gelelectrophoresis and transferred to nitrocellulose filter membranes. The membranes were blocked in 5\% non-fat milk in Tris-buffered saline containing $0.1 \%$ Tween 20 (TBST) for $3 \mathrm{~h}$ at room temperature and then incubated overnight at $4{ }^{\circ} \mathrm{C}$ with specific anti-OPN (diluted 1:1, 000; Abcam, Cambridge, UK), anti-cathepsin K, anti-NF- $\mathrm{BB}$, or anti-MMP9, antibody (diluted 1:500; Elabscience, Wuhan, China), anti-RANKL, anti-caspase3, anti-PARP1 or anti-OPG antibody (diluted 1:400; Elabscience), or antiGAPDH antibody (diluted 1:5, 000; Abcam). After the membrane was washed three times with TBST (10 min each wash), it was incubated with horseradish peroxidase (HRP)-conjugated anti-rabbit, anti-goat, or anti-mouse secondary antibody (diluted 1:2,000) for $45 \mathrm{~min}$ at room temperature. The membranes were processed with enhanced chemiluminescence (ECL) and visualized with Bio-Rad Laboratories. 


\section{Cellular Physiology Cell Physiol Biochem 2018;49:884-898 and Biochemistry Published \begin{tabular}{l|l} 
(c) 2018 The Author(s). Published by S. Karger AG, Basel \\
wor: 10.1159/000493219
\end{tabular} \\ Dong et al:: Osteopontin Promotes Bone Destruction in Periapical Periodontitis}

\section{Immunohistochemistry}

The mandibular tissues were decalcified at room temperature for 21 days with 4.13\% EDTA and washed three times with phosphate-buffered saline (PBS). Sucrose (20\%) was added and the samples stored at $4{ }^{\circ} \mathrm{C}$. Serial sections $(8 \mu \mathrm{m})$ were prepared from the mandibular tissues. A working solution of normal goat serum was added and the sections were incubated for $60 \mathrm{~min}$ at room temperature. The samples were probed overnight at $4{ }^{\circ} \mathrm{C}$ with primary antibodies directed against OPN (diluted 1:100), cathepsin K, NF$\kappa B$, or MMP9 (diluted 1:50), RANKL and OPG (diluted 1:200), or GAPDH and $\beta$-actin (diluted 1:150), and immunoglobulin G (IgG) was used as the negative control. The sections were washed with PBS and incubated with a biotinylated secondary antibody for $40 \mathrm{~min}$ at $37^{\circ} \mathrm{C}$. The sections were washed with PBS and then incubated with streptavidin horseradish peroxidase for $40 \mathrm{~min}$ at $37^{\circ} \mathrm{C}$. Positive reactions were visualized with a 3, 3'-diaminobenzidine tetrahydrochloride (DAB) -labeled peroxidase substrate for 6 min. Positive cells were observed with microscopy. The total number of positive cells (20x objective lens, units/lesion) in the proximal alveolar bone region $(n=5)$ of the mandibular first molar were counted under an Olympus BX43 light microscope. The mean number of positive cells in five consecutive sections was recorded for each specimen.

\section{Animal experiments}

A total of 40 wild-type male C57BL/6J mice, weighing 20-22g, were supplied by Dalian Medical University, and were housed in an animal control facility under a $12 \mathrm{~h}$ light/dark cycle, with a mean illumination of $80 \mathrm{l} \times$. The animals were maintained at $22 \pm 2{ }^{\circ} \mathrm{C}$. All procedures were conducted in accordance with the Institutional Guidelines for the Care and Use of Laboratory Animals of Dalian Medical University, and all protocols were approved by the Institutional Animal Care and Use Committee of Dalian Medical University. After odontotrypy of the right mandibular first molar with small ball dental drill, the mice were randomly divided into four groups, each of which contained eight mice. At each time point $(0,1,2,3$, and 4 weeks), the mandibular apical tissues of four mice were prepared for micro computed tomography (micro-CT), enzyme histochemistry, and immunohistochemical staining, and those from another four mice were used for real-time PCR. The specific primers used were: OPN, 5'-ACACTTTCACTCCAATCGTA-3' and 5'-TGCCCTTTCCGTTGTTGTCC-3'; $N F-\kappa B$, 5'-TGTCAGAGCCCTTGTAACTG-3' and 5'-CTGTGGGTAGGATTTCTTGT-3'; 5'-GCCCTGGAACTCACACGACA-3' and 5'-TTGGAAACTCACACGCCAGAAG-3'; cathepsin $K$, 5'-CACCCAGTGGGAGCTATGGAA-3' and 5'-GCCTCCAGGTTATGGGCAGA-3'; and GAPDH, 5'-AGGTCGGTGTGAACGGATTTG-3' and 5'-TGTAGACCATGTAGTTGAGGT-3'. The week 0 group was used as the control group.

\section{Micro-CT}

The apical bone tissue of the first molar was scanned with Xradia MicroXCT-400 (Xradia, CA, USA). The scanning conditions were $109 \mathrm{kV}$ and $9 \mathrm{~W}$, the exposure time was $5 \mathrm{~s}$, and the pixel value was $20.0 \mu \mathrm{m}$. The data were saved as DICOM data. We used the Mimics 16.0 software (Materialize, Belgium) to reconstruct the volume of the first molar periapical bone destroyed and used the software to calculate the three-dimensional volumes.

\section{Enzyme histochemistry}

The staining buffer was prepared with $0.5 \mathrm{~mL}$ of Fast Garnet GBC Base, $0.5 \mathrm{~mL}$ of sodium nitritep, 45 $\mathrm{mL}$ of distilled deionized $\mathrm{H}_{2} \mathrm{O}, 0.5 \mathrm{~mL}$ of AS-BI phosphate, $2 \mathrm{~mL}$ of acetate, and $1.0 \mathrm{~mL}$ of tartrate, according to the instructions of the Acid Phosphatase, Leukocyte (TRAP) Kit (387A-1K; Sigma-Aldrich, St. Louis, MO, USA). The tablets were immersed in the fixative for $30 \mathrm{~s}$ and then placed in the staining solution and incubated at $37^{\circ} \mathrm{C}$ for $1 \mathrm{~h}$. The slices were then placed in Hematoxylin Solution, Gill No. 3 for 2 min. The osteoclasts in the apical lesions of the mandibular first molar $(n=5)$ were counted from photographs taken with an Olympus BX43 light microscope. Three noncontiguous sections were randomly selected to represent each tissue sample.

\section{Cell culture}

RAW264.7 and MC3T3-E1 cells (American Type Culture Collection, Manassas, VA, USA) were grown in Dulbecco's modified Eagle's medium (DMEM, Invitrogen, Carlsbad, CA, USA) supplemented with $10 \%$ fetal bovine serum, $0.005 \mathrm{mg} / \mathrm{mL}$ insulin, $100 \mathrm{U} / \mathrm{mL}$ penicillin, and $100 \mu \mathrm{L} / \mathrm{mL}$ streptomycin. The cells were maintained at $37{ }^{\circ} \mathrm{C}$ under $5 \% \mathrm{CO}_{2}$ in humidified air. The Cells $\left(1 \times 10^{6}\right)$ were seeded into 6 -well plates, and when they had reached $80 \%$ confluence, they were washed three times with PBS. Osteoclasts were induced with $100 \mathrm{ng} / \mathrm{mL}$ RANKL (Abcam). The tartrate-resistant acid phosphatase (TRAP) activity was detected with a Tartrate Resistnt Acid Phosphatase Colorimetric Assay Kit, according to the manufacturer's instructions to determine the morphological characteristics of the osteoclasts. The TRAP activity was detected with a 


\section{Cellular Physiology Cell Physiol Biochem 2018:49:884-898 and Biochemistry Published \begin{tabular}{l|l} 
DOI: 10.1159/000493219 2018 The Author(s). Published by S. Karger AG, Basel \\
and
\end{tabular} \\ Dong et al.: Osteopontin Promotes Bone Destruction in Periapical Periodontitis}

TRAP kit. The cells in each well were incubated with $40 \mu \mathrm{L}$ of reaction buffer and $5 \mu \mathrm{L}$ Tartrate Solution for $2 \mathrm{~min}$, and $100 \mu \mathrm{L}$ of the reaction stop solution was added to each well to stop the reaction. The absorbance was measured at $450 \mathrm{~nm}$. The expression levels of the mRNAs of osteoclast markers cathepsin $K$, interleukin 6 (IL-6), and TRAP were determined with real-time PCR. An in vitro model of osteoblasts was established. MC3T3-E1 cells in the logarithmic growth phase were adjusted to $1.5 \times 10^{6} / \mathrm{mL}$, and the cells were cultured in DMEM containing osteogenic induction solution (osteogenic inducer: $10 \mathrm{nmol} / \mathrm{L}$ dexamethasone, $10 \mathrm{mmol}$ / L $\beta$-sodium glycerophosphate, $50 \mu \mathrm{g} / \mathrm{mL}$ vitamin C). The alkaline phosphatase (ALP) activity was detected with an Alkaline Phosphatase Assay kit (Beyotime Biotechnology, China). The expression of the RUNX-2 and ALP mRNAs was detected with real-time PCR. The cells were stained with Alizarin Red (Sanggon Biotech) after 21 days to observe the formation of calcified nodules in the osteoblasts. The medium was removed from the plates and the cells were washed three times with PBS. The cells were fixed with 95\% ethanol for 10 min and incubated with Alizarin Red dye for $30 \mathrm{~min}$, and the results were recorded after drying. The specific primers used were: RUNX-2, 5'-CCGAAATGCCTCCGCTGTTATG-3' and 5'-GGATTTGTGAAGACTGTTATGGT-3'; $A L P, \quad$ 5'-CTGATGTGGAATACGAACTGGA-3' and 5'-AGTGGGAATGCTTGTGTCTGG-3'; IL-6, 5'-GACAAAGCCAGAGTCCTTCAGAG $-3^{\prime}$ and 5'-TCCTTAGCCACTCCTTCTGTGAC $-3^{\prime}$ and TRAP, 5'-GGGTCACTGCCTACCTGTGT-3' and 5'-TCATTTCTTTGGGGCTTATCTC-3'.

\section{Cell Counting Kit-8 (CCK-8)}

The cells were seeded in 96 -well plates at $100 \mu \mathrm{L}$ per well $\left(\mathrm{n}=10^{3}\right.$ cells) and cultured for $24 \mathrm{~h}$ before $10 \mu \mathrm{L}$ of CCK-8 solution was added to each well. The plates were incubated for $4 \mathrm{~h}$. Absorbance (OD) at 450 nm was measured.

Short interfering RNA (siRNA) knockdown and vector-mediated overexpression experiments

RAW264.7 and MC3T3-E1 cells were seeded in 6-well plates. For the knockdown experiments, siRNA targeting the Opn gene (OPN-siRNA; 50 or $200 \mathrm{nmol} /$ well) and a negative control siRNA were purchased from GenePharma (Suzhou, China). For the overexpression experiments, an OPN-overexpressing vector (Over-OPN plasmid; 100 or $200 \mathrm{nmol} /$ well) was purchased from GenePharma. RAW264.7 and MC3T3-E1 cells were transfected with the OPN-siRNA or Over-OPN plasmid using Xfect RNA Transfection Reagent and Xfect Transfection Reagent (TaKaRa) respectively. The transfection efficiency was determined with realtime PCR and western blotting.

\section{Indirect immunofluorescent staining}

The cells were fixed with ice-cold methanol for $10 \mathrm{~min}$ and rinsed three times with PBS for 5 min each. A working solution of normal goat serum was added, the samples were incubated for 20 min at room temperature, They were then probed with the primary antibody (anti-NF- $\kappa \mathrm{B}$, diluted 1:100) overnight at $4^{\circ} \mathrm{C}$, and IgG was used as the negative control. All antibodies were diluted with PBS. F-actin was detected with fluorescein isothiocyanate (FITC)-conjugated phalloidin (Sigma-Aldrich) diluted in phosphate buffer (50 g/ $\mathrm{mL}$ ). The cells were incubated with 4', 6-diamidino-2-phenylindole (DAPI) for $5 \mathrm{~min}$ at room temperature and washed again three times. The expression of NF- $\kappa \mathrm{B}$ in the nucleus was observed with microscopy.

\section{Statistical analysis}

Data are expressed as mean \pm SEM. Significant differences between test groups were analyzed with one-way analysis of variance and the Student-Newman-Keuls test, $P<0.05$ was considered to be significant.

\section{Results}

Elevated expression of $O P N, N F-\kappa B, M M P 9$, and cathepsin $K$ in chronic periapical periodontitis

Real-time PCR showed that the expression of $O P N$, nuclear factor kappaB $(N F-\kappa B)$, matrix metalloproteinase 9 (MMP9), and cathepsin K (CTSK) was significantly higher in the chronic periapical periodontitis patients than in the control subjects $(\mathrm{P}<0.05)$ (Fig. 1A). A correlation analysis showed that $O P N$ mRNA expression correlated with that of $N F-\kappa B$ and cathepsin $K$, but not with that of $M M P 9$ (Fig. 1B). Immunohistochemistry and western blotting showed that the expression of OPN, NF- $\mathrm{KB}, \mathrm{MMP9}$, and cathepsin K was significantly higher in the group with chronic periapical periodontitis than in the control group $(\mathrm{P}<0.05)$ (Fig. 1C-D). 


\section{Cellular Physiology Cell Physiol Biochem 2018;49:884-898 $\begin{array}{lll}\text { DOI: 10.1159/000493219 } & \text { ( } 2018 \text { The Author(s). Published by S. Karger AG, Basel } \\ \text { and Biochemistry } & \text { Published online: } 5 \text { September, } 2018 \text { www.karger.com/cpb }\end{array}$

\section{Mouse model of periapical periodontitis analyzed with micro-CT}

Micro-CT showed that the volume of bone destruction in the model mice was greatest at 1-4 weeks after infection. Fig. 2A shows images of the first molar in the horizontal, coronal, and and sagittal planes. At week 0, the mandibular bones of the mice had a complete periodontal tissue structure, and the periodontal ligament had not widened. After infection for 1 week, the periodontal ligament was slightly widened and a shadow was apparent on the apical bone, indicating a small amount of bone destruction. After infection for 2-4 weeks, the volume of bone destruction in the mice gradually increased. However, there was no significant difference between weeks 3 and 4 ( $P$ > 0.05; Fig. 2B).

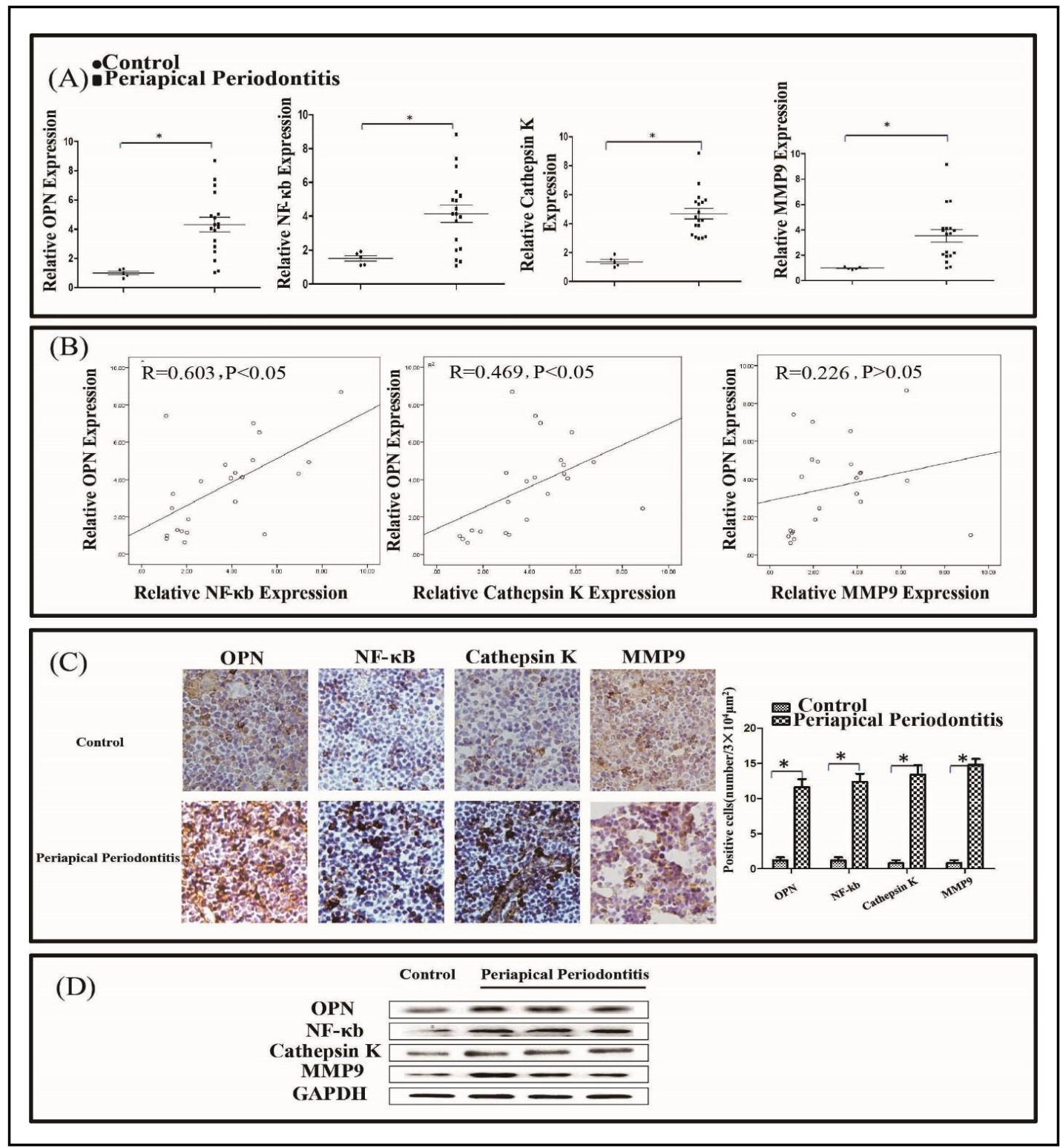

Fig. 1. Expression of $O P N, N F-\kappa B, M M P 9$, and cathepsin $K$ in chronic periapical periodontitis. (A) Realtime PCR was used to analyze OPN, NF- $\kappa B, M M P 9$, and cathepsin K expression in patients with chronic periapical periodontitis. (B) Correlation of NF- $\mathrm{kB}, \mathrm{MMP9}$, and cathepsin K expression with OPN expression. A significant correlation was found between OPN and NF- $\kappa$ B mRNAs ( $r=0.603$ ) and between OPN and cathepsin $\mathrm{K}$ mRNAs ( $\mathrm{r}=0.469$ ). (C) Immunohistochemistry showed that the expression of OPN, NF- $\kappa B$, MMP9, and cathepsin $\mathrm{K}$ was significantly higher in the chronic periapical periodontitis group than in the control group. All images are presented at $200 \times$ magnification. (D) Western blotting detection of OPN, NF$\kappa \mathrm{B}, \mathrm{MMP9}$, and cathepsin $\mathrm{K}$ during chronic periapical periodontitis, ${ }^{*} \mathrm{P}<0.05$. 


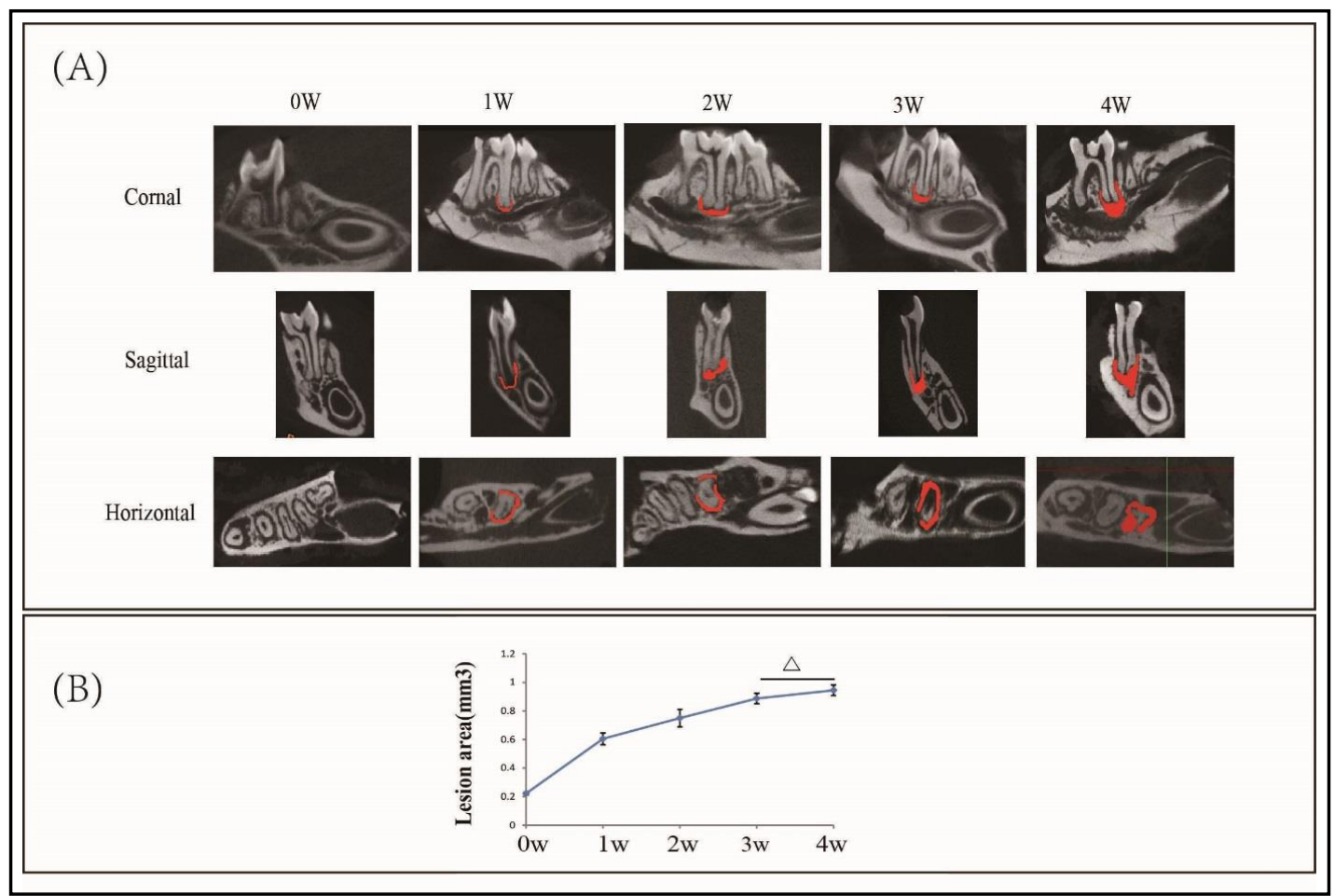

Fig. 2. Micro-CT analysis of bone destruction in mice with periapical lesions in weeks 0-4. (A) MicroCT was used to analyze mandibular periapical periodontitis from 0 to 4 weeks. Red area represents the periapical bone area. (B) Statistical analysis of the bone resorption volume from 0 to 4 weeks. There was no statistically significant difference between 3 and 4 weeks $(\Delta: \mathrm{P}>0.05)$, whereas the differences between the other groups were statistically significant $(\mathrm{P}<0.05)$.

Expression of OPN, NF- $\kappa B, M M P 9$, and cathepsin $K$ and the numbers of osteoclasts in mice with periapical periodontitis

Real-time PCR and immunohistochemistry showed that the expression of OPN, NF- $\kappa \mathrm{B}$, and cathepsin $\mathrm{K}$ increased from week 1 to week 2 in the model mice, and peaked in week 2. At 3-4 weeks, their expression decreased. However, the expression of MMP9 increased continuously, peaking in week 4. TRAP staining showed that the expression of osteoclasts peaked in week $2(\mathrm{P}<0.05)$. TRAP-positive cells increased substantially from week 1 to week 2 and then gradually decreased from week 2 to week $4(\mathrm{P}<0.05$; Fig. 3A, B, and D). A correlation analysis showed that OPN expression correlated with NF- $\mathrm{KB}$, cathepsin $\mathrm{K}$, and TRAP expression $(\mathrm{P}<0.01)$, but only slightly with MMP9 expression $(\mathrm{P}<0.05$; Fig. $3 \mathrm{C})$.

Effects of LPS on the differentiation and activity of induced RAW264.7 and MC3T3-E1 cells

An in vitro osteoclast induction model was established. Using RAW264.7 cells in the logarithmic growth phase, the cell concentration was adjusted to $1.5 \times 10^{4} / \mathrm{ml}$, and the cells were induced with $100 \mathrm{ng} / \mathrm{mL}$ RANKL. TRAP staining was performed to determine the morphological characteristics of the osteoclasts. The number of TRAP-positive multinucleate osteoclasts ( $\mathrm{n} \geq 3$ nuclei) was counted under a microscope. The number of osteoclasts increased significantly for 5 days after induction, indicating the successful differentiation of the RANKL-induced osteoclast precursor RAW264.7 cells into osteoclast cells (Fig. 4A).

Fig. 4B shows that the expression of the mRNAs of osteoclast markers cathepsin $K$, interleukin $6(I L-6)$, and TRAP had increased after induction for 5 days. MC3T3-E1 cells in the logarithmic growth phase were cultured in DMEM containing osteogenic induction solution for $0,3,5$, or 7 days, stained with Alizarin Red, and their ALP activity measured. Alizarin Red showed that the osteoblasts were induced after 21 days, when mineralized nodules were observed with the naked eye and red calcite was observed under an optical microscope (Fig. 4 C-D). ALP is a marker of the early differentiation in MC3T3-E1 cells, and its main role is to 


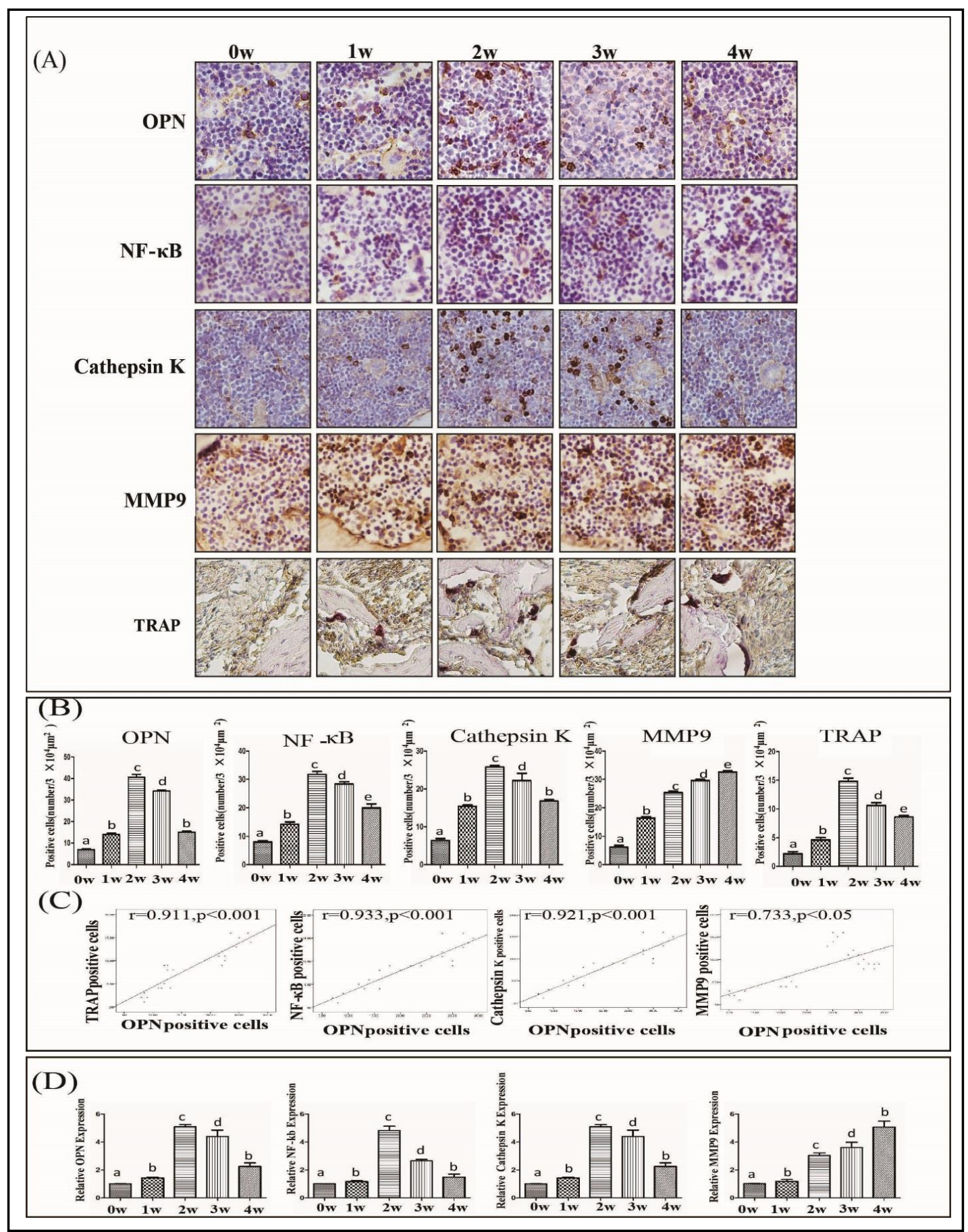

Fig. 3. Expression of $\mathrm{OPN}, \mathrm{NF}-\kappa \mathrm{B}, \mathrm{MMP9}$, cathepsin $\mathrm{K}$ and numbers of osteoclasts in model mice. (A) Immunohistochemical staining for OPN, NF- $\mathrm{B}, \mathrm{MMP}$, cathepsin $\mathrm{K}$ and TRAP in mice. (B) Statistical analysis of the immunohistochemistry results. Different letters indicate statistically significant differences $(\mathrm{P}<0.05)$. (C) Correlation analysis showed that OPN levels correlated with those of NF- $\kappa B$, cathepsin $\mathrm{K}$, and TRAP $(\mathrm{P}<0.01)$, but only slightly with that of MMP9 $(\mathrm{P}<0.05)$. (D) Statistical analysis of real-time PCR. Different letters indicated statistically significant differences $(\mathrm{P}<0.05)$. Experiments were repeated four times. Data are as means $\pm \mathrm{SD}, * \mathrm{P}<0.05$. All images are presented at $200 \times$ magnification. 


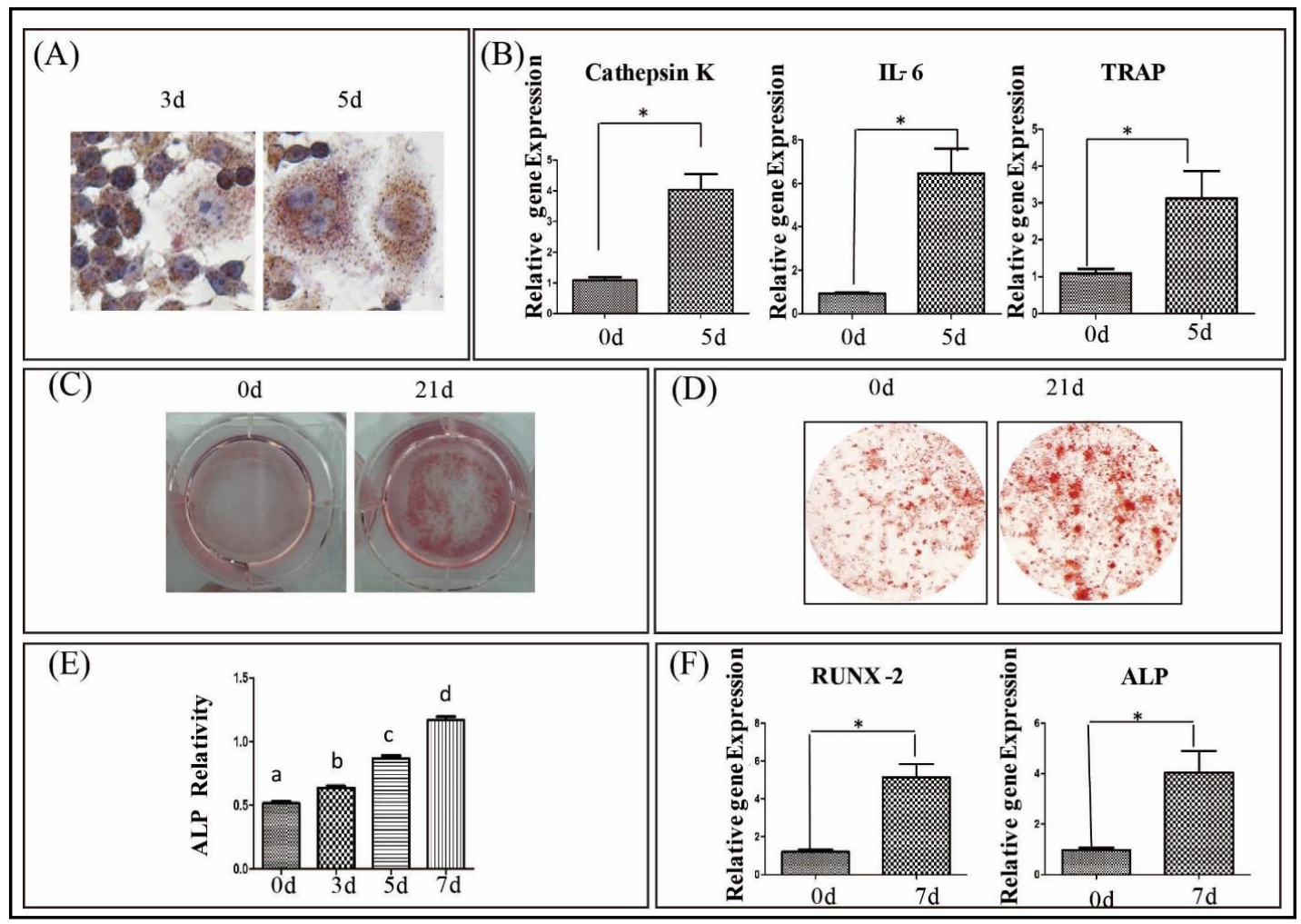

Fig. 4. Osteoclast and osteoblast induction models were established in vitro. (A) TRAP staining was performed to determine the morphological characteristics of the osteoclasts. On the $3^{\text {rd }}$ day of RAW264.7 cells induction, the number of nuclei had increased. On the $5^{\text {th }}$ day, the cell number had increased significantly, the cell volume had increased, and patchy pseudopods were observed. TRAP staining showed multinucleate cells, and pseudopodia. (B) Messenger RNA expression of TRAP, cathepsin K, and IL-6 had increased in RANKL-treated RAW264.7 cells on day $5,{ }^{*} \mathrm{P}<0.05$. Data are means \pm SD. (C) After the cells were cultured for 21 days, they were stained with Alizarin Red to identify MC3T3-E1 cells, which contained brick red particles after 21 days in culture. (D) Microscopy was used to observe the sizes of the calcium nodules, most of which were round or oval. All images are presented at 40× magnification. (E) MC3T3-E1 cells were induced for 7 days, by which time their ALP activity had increased. Different letters indicate results that were statistically significantly different $(\mathrm{P}<0.05)$. (F) Real-time PCR showed that RUNX-2 and ALP mRNA expression increased, ${ }^{*} \mathrm{P}<0.05$.

promote osteoblast maturation and calcification. In the initial stage of culture, the level of secreted ALP was low, but the content of ALP gradually increased with time, peaking on day 7 (Fig. 4E). The mRNA expression of the osteoblast markers RUNX-2 and ALP increased after induction for 5 days (Fig. 4F). A CCK-8 assay was used to determine the optimal concentration of LPS to be used to estimate its effects on RAW264.7 and MC3T3-E1 cells. We tested various different concentrations of LPS $\left(0,1,10,10^{2}, 10^{3}\right.$, or $\left.10^{4} \mathrm{ng} / \mathrm{mL}\right)$. The results showed that $10^{2} \mathrm{ng} / \mathrm{mL}$ LPS was the optimal concentration for RAW264.7 cells, and $10^{3} \mathrm{ng} / \mathrm{mL}$ LPS was the best concentration for MC3T3-E1 cells (Fig. 5A). After $24 \mathrm{~h}$ in culture, $10^{2} \mathrm{ng} / \mathrm{mL}$ LPS increased the proliferation and TRAP activity of the RAW264.7 cells, and both parameters were even higher after $48 \mathrm{~h}(\mathrm{P}<0.05)$, indicating that LPS promoted the proliferation and differentiation of RAW264.7 cells. In contrast, $10^{3} \mathrm{ng} / \mathrm{mL}$ LPS inhibited the proliferation and differentiation of MC3T3-E1 cells, and cellular proliferation and ALP activity were significantly lower after $48 \mathrm{~h}$ than after $24 \mathrm{~h}$ ( $\mathrm{P}<0.05$; Fig. 5B-C). Western blotting showed that the expression of caspase 3 and poly 'ADP-ribose polymerase 1 (PARP1) increased when MC3T3-E1 cells were treated by LPS (Fig. 5D), indicating that LPS promoted the apoptosis of MC3T3-E1 cells. Real-time PCR and western blotting showed that the expression of OPN, NF- $\mathrm{KB}, \mathrm{MMP9}$, and cathepsin K was higher in the LPS-treated cells than in the control cells (Fig. 5E-F). 


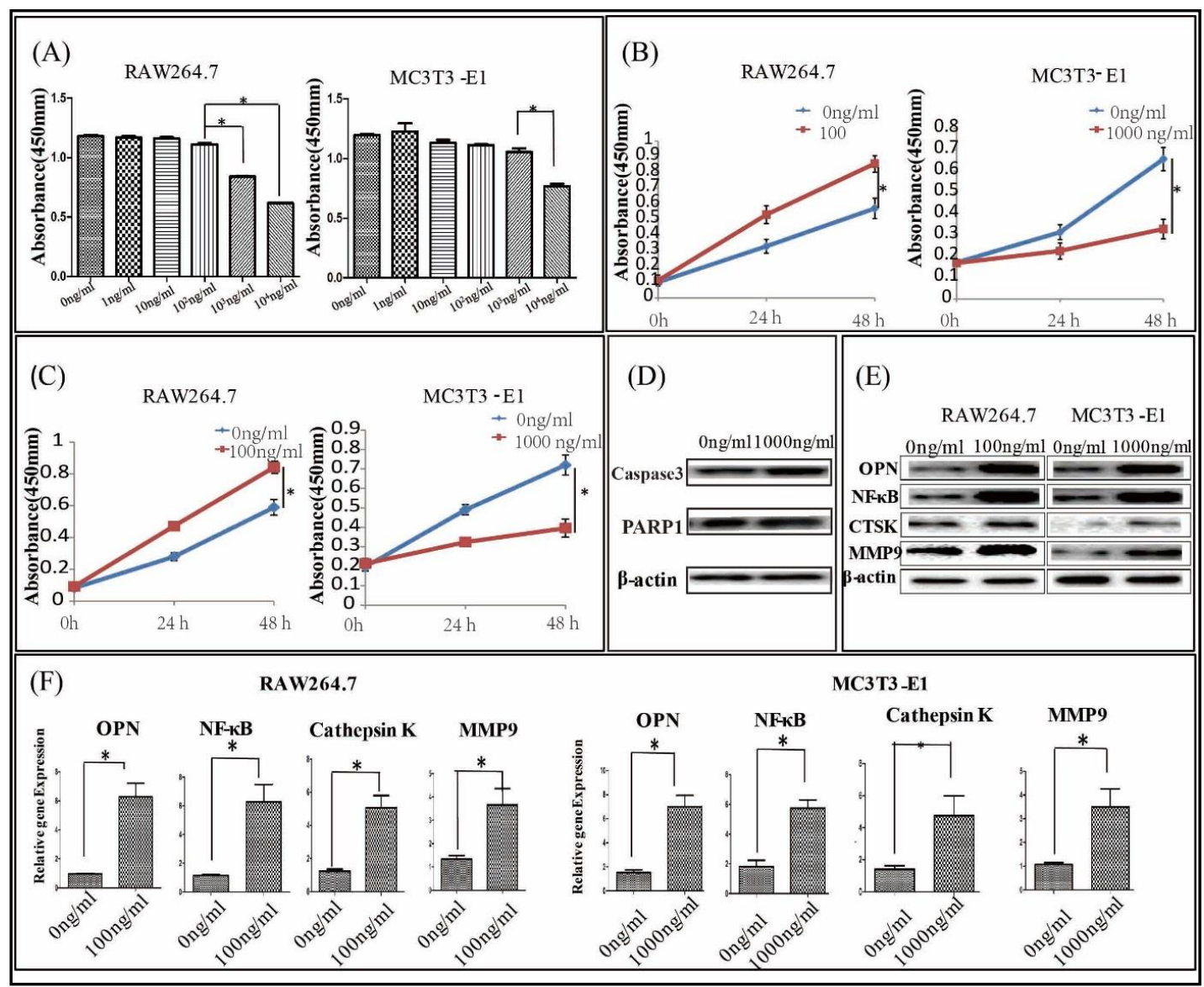

Fig. 5. Effects of LPS on the proliferation and differentiation of induced RAW264.7 and MC3T3-E1 cells. (A) CCK-8 was used to detect the optimal concentrations of LPS with which to test its effects on RAW264.7 and MC3T3-E1 cells. (B) LPS $\left(10^{2} \mathrm{ng} / \mathrm{mL}\right)$ increased the proliferation of RAW264.7 cells, whereas LPS $\left(10^{3}\right.$ $\mathrm{ng} / \mathrm{mL}$ ) reduced the proliferation of MC3T3-E1 cells. (C) LPS increased the differentiation of RAW264.7 cells, but reduced that of the MC3T3-E1 cells $\left({ }^{*} \mathrm{P}<0.05\right)$. (D) Western blotting showed that the expression of caspase 3 and PARP1 increased when MC3T3-E1 cells were treated by LPS. (E) Western blotting showed that the expression of OPN, NF- $\mathrm{KB}, \mathrm{MMP9}$, and cathepsin K was higher in the LPS-treated cells than in the control cells. (F) Expression of OPN, NF- $\mathrm{B}, \mathrm{MMP9}$, and Cathepsin K mRNAs in the LPS-treated RAW264.7 and MC3T3-E1 cells, ${ }^{*} \mathrm{P}<0.05$. Data are means \pm SD.

OPN regulates factors involved in bone destruction through the NF- $\kappa B$ signaling pathway in vitro

RAW264.7 and MC3T3-E1 cells were transfected with the OPN-siRNA or Over-OPN plasmid. Real-time PCR and western blotting confirmed the successful transfection of the plasmids (Fig. 6A-D). The effects of OPN on the proliferation of the two kinds of cells were detected with a CCK-8 assay. The effects of OPN on the differentiation of the two kinds of cells were detected by measuring TRAP and ALP expression. The CCK-8 assay was used to construct a cell growth curve. The absorbance of the RAW264.7 and MC3T3-E1 cells were measured at 0,24 , and $48 \mathrm{~h}$. The average value at each time point was used to construct a line chart. The growth of the RAW264.7 cells was significantly inhibited after OPN was silenced, whereas the growth of the MC3T3-E1 cells was significantly enhanced. After the transfection of OverOPN, the growth of the RAW264.7 cells was significantly enhanced, whereas the growth of the MC3T3-E1 cells was significantly inhibited (Fig. 6E). Western blotting showed that the expression of caspase 3 and PARP1 increased when the RAW264.7 cells were transfected with OPN-siRNA and the MC3T3-E1 cells were transfected with Over-OPN (Fig. 6F). This result shows that OPN promoted the growth of RAW264.7 cells, but inhibited the growth of 


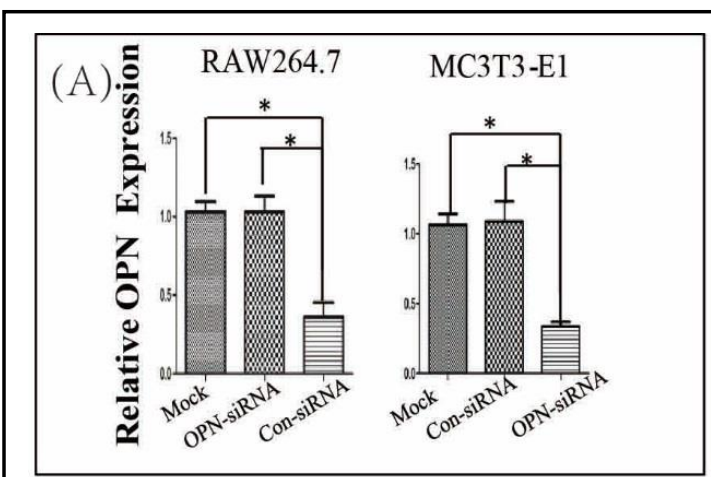

(B)
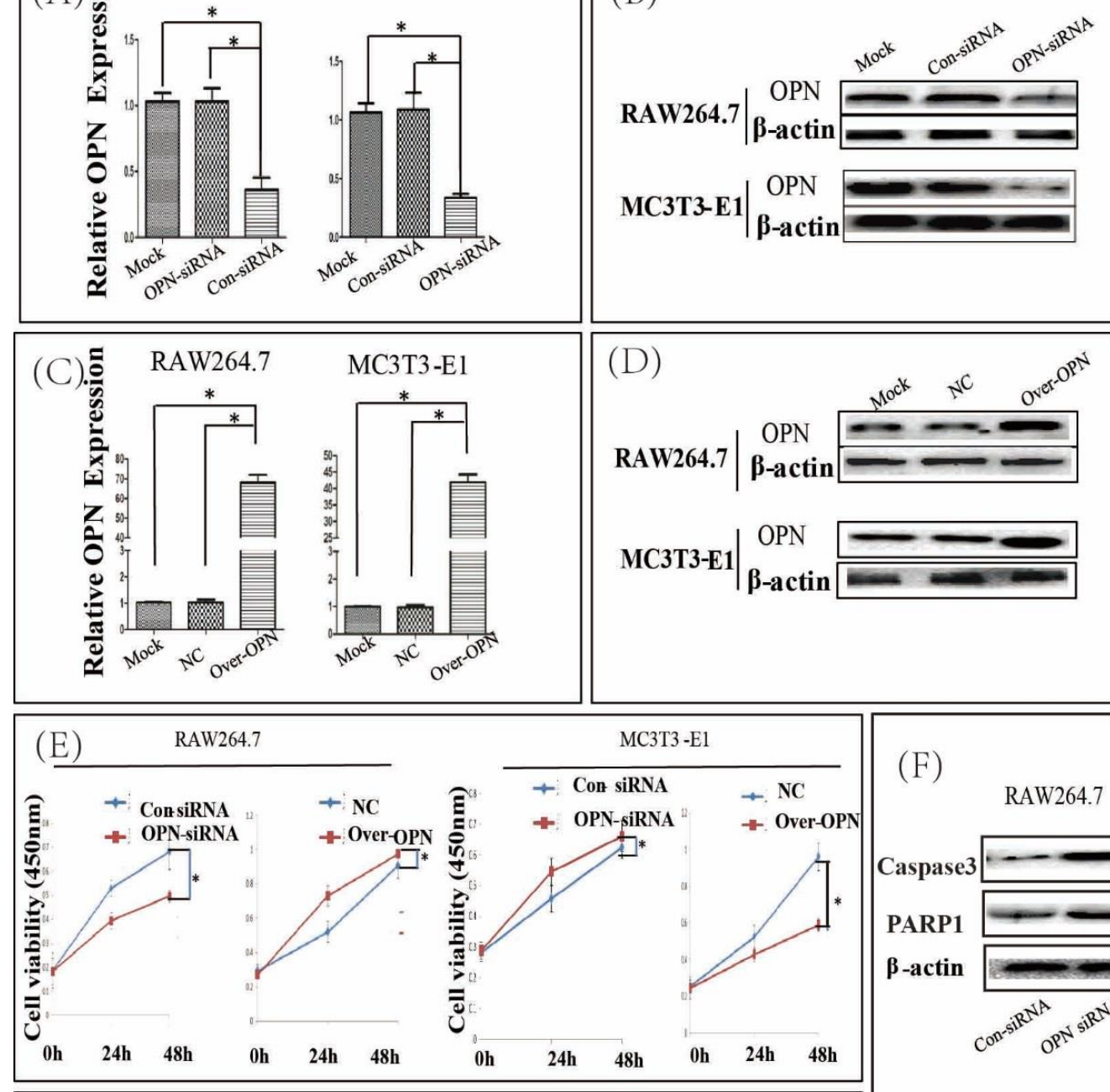

( F)
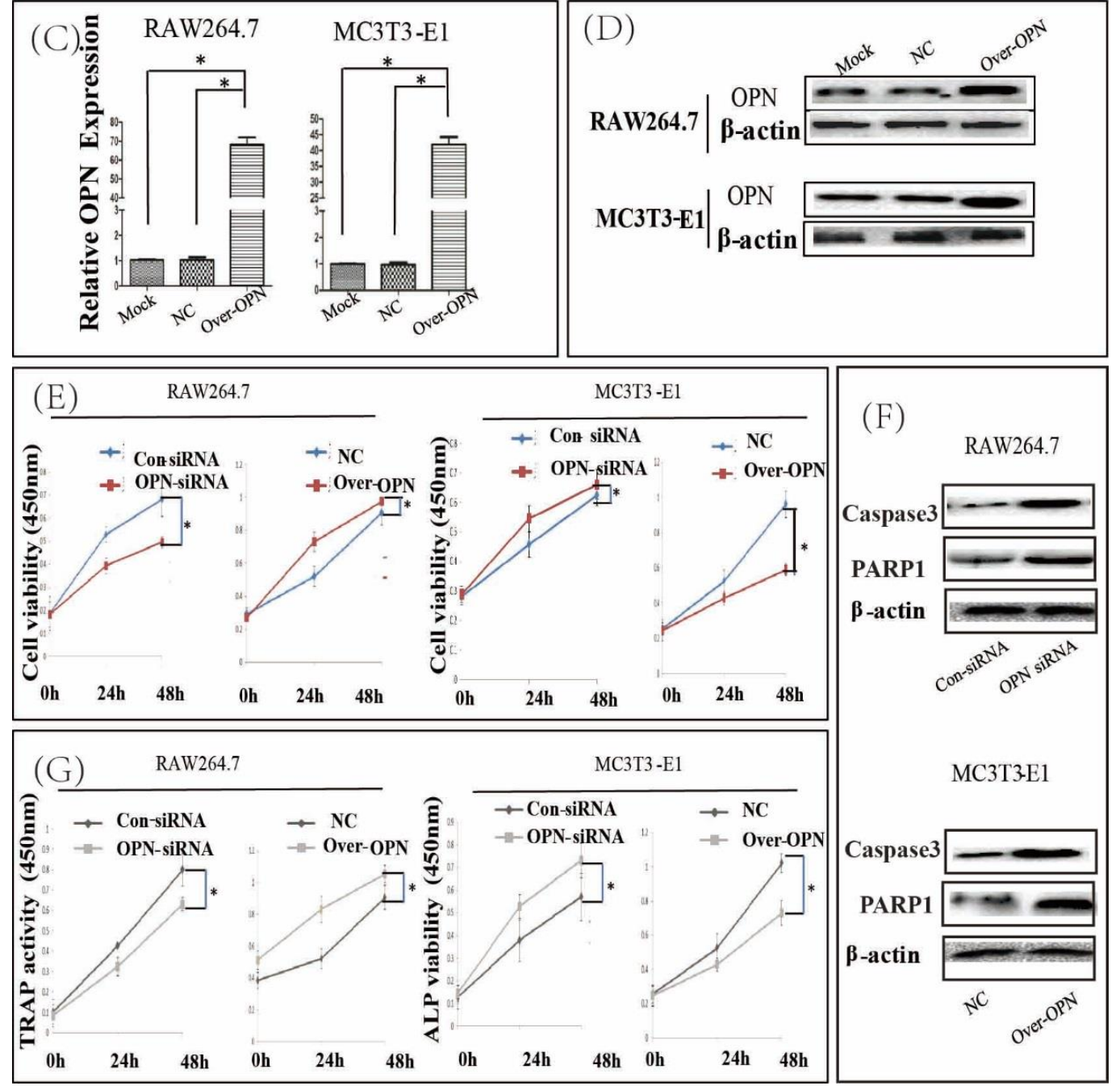

Fig. 6. OPN promotes the proliferation and differentiation of RAW264.7 cells and inhibits the proliferation and differentiation of MC3T3-E1 cells. (A-D) Real-time PCR and western blotting demonstrated the successful transfection of the OPN-siRNA and Over-OPN plasmids. (E) The CCK-8 assay was used to construct a cell growth curve. (F) Western blotting showed that the expression of caspase 3 and PARP1 increased when MC3T3-E1 cells were transfected with Over-OPN. (G) TRAP and ALP measurements showed that OPNsiRNA reduced the differentiation of RAW264.7 cells, whereas Over-OPN enhanced their differentiation. In contrast, OPN-siRNA (OPN silencing) enhanced the differentiation of MC3T3-E1 cells, whereas Over-OPN reduced it $(* \mathrm{P}<0.05)$.

\section{KARGER}


MC3T3-E1 cells. The result for TRAP shows that OPN-siRNA reduced the differentiation of RAW264.7 cells, in contrast to the effect of Over-OPN. The results for ALP showed that OPNsiRNA enhanced the differentiation of MC3T3-E1 cells, whereas Over-OPN reduced it (Fig. $6 G)$.

Western blotting demonstrated that the expression of NF- $\mathrm{kB}$, MMP9, and cathepsin $\mathrm{K}$ decreased when RAW264.7 cells were transfected with OPN-siRNA. However, the levels of

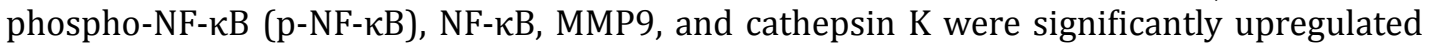

Fig. 7. OPN regulates factors associated with bone destruction through the NF- $\mathrm{B}$ signaling pathway in vitro. (A) Expression of NF- $\mathrm{kB}$, RANK, and cathepsin K decreased in RAW264.7 cells after their transfection with OPN-siRNA, but increased significantly after their transfection with Over-OPN. After PDTC treatment, the overall trends in expression were significantly reduced. (B) Immunofluorescence showed that when the cells were transfected with OPN-siRNA, the amount of NF- $\kappa B$ in the nucleus decreased. When the cells were transfected with Over-OPN, the amount of NF- $\kappa B$ in the nucleus increased. After the addition of PDTC, $\mathrm{NF}-\kappa \mathrm{B}$ expression in the nucleus decreased. All images are presented at $200 \times$ magnification. (C) OPN may accelerate the nuclear translocation of NF- $\kappa \mathrm{B}$ via different upstream pathways, and its translocation is necessary for the regulatory activities of the NF- $\kappa$ B pathway. Therefore, we suggest that OPN regulates these proteins by activating the NF- $\kappa \mathrm{B}$ signaling pathway.

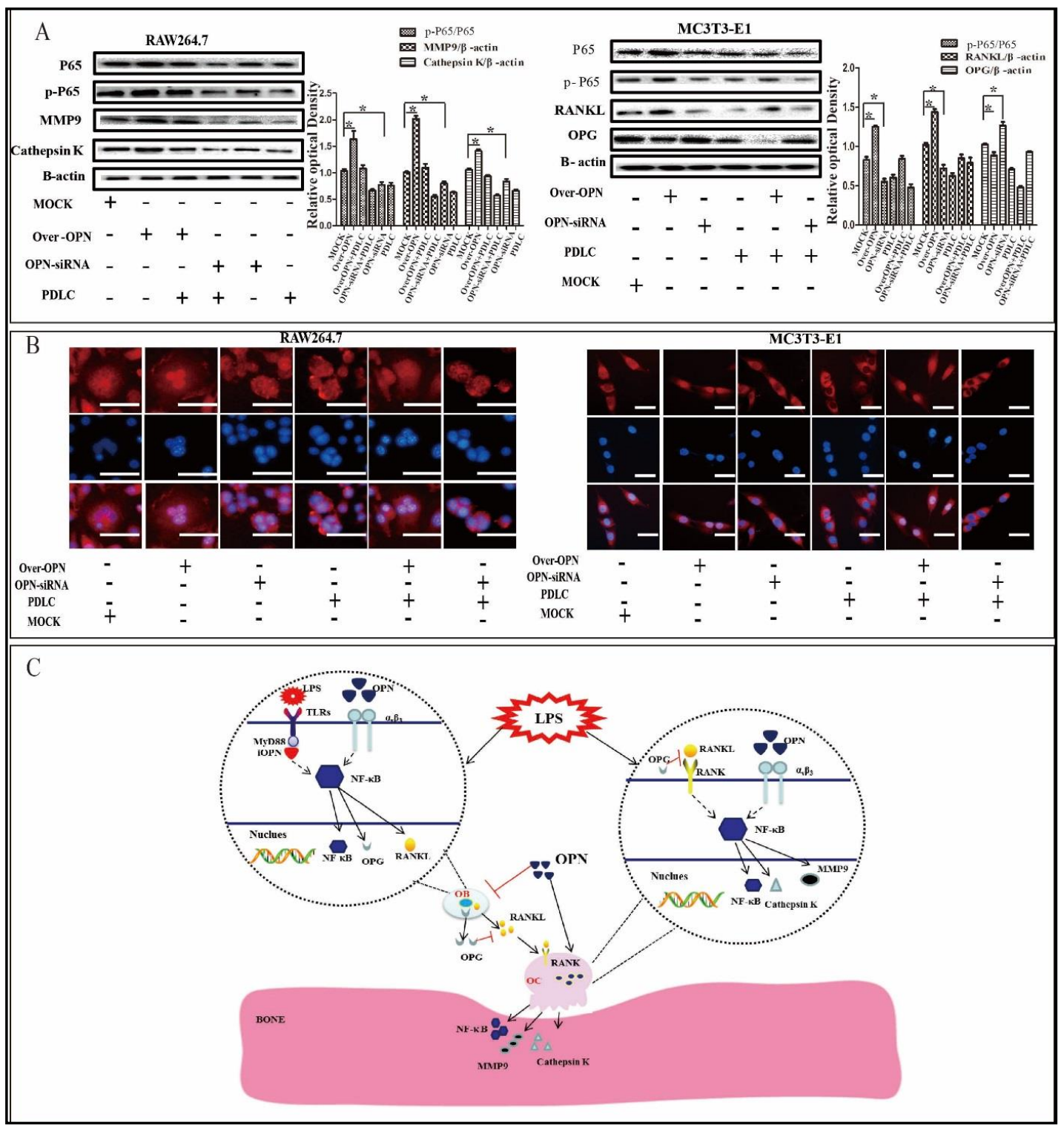




\section{Cellular Physiology Cell Physiol Biochem 2018:49:884-898

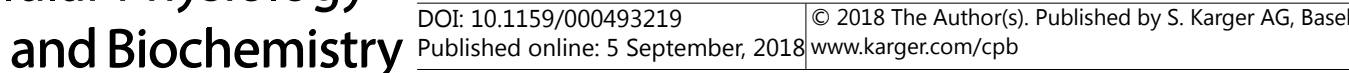 \\ Dong et al.: Osteopontin Promotes Bone Destruction in Periapical Periodontitis}

when the cells were transfected with Over-OPN. When MC3T3-E1 cells were transfected with OPN-siRNA, western blotting showed that the p-NF- $\kappa B, N F-\kappa B$, and RANKL levels decreased, whereas the expression of the bone-formation marker osteoprotegerin (OPG) increased. In MC3T3-E1 cells transfected with Over-OPN, the expression of NF-кB and RANKL increased, whereas the expression of OPG decreased. When pyrrolidine dithiocarbamate (PDTC), an inhibitor of NF- $\mathrm{KB}$, was used to pretreat the transfected cells, the expression of these markers showed the same trends. However, their expression decreased after PDTC treatment, indicating that PDTC inhibited the expression of NF- $\kappa \mathrm{B}$, and that OPN positively regulated NF- $\kappa B$ expression (Fig. 7A). In normal cells, NF- $\kappa B$ was detected mainly in the cytoplasm, with weak expression in the nucleus. Twenty-four hours after LPS treatment, the nucleus showed strong red fluorescence, and the cytoplasmic expression of NF- $\kappa B$ was reduced. After transfection with Over-OPN, the fluorescence of nuclear NF- $\kappa B$ was significantly enhanced. However, the fluorescence of NF- $\kappa B$ in the nucleus decreased significantly after OPN was silenced. After PDTC treatment, the fluorescence of NF- $\kappa B$ in the nucleus significantly decreased or even disappeared, and there was strong red fluorescence in the cytoplasm (Fig. $7 \mathrm{~B})$. These results suggested that LPS, an endotoxin, activated the NF- $\mathrm{KB}$ signaling pathway. OPN promoted the nuclear transfer of NF- $\kappa B$, so OPN regulated the expression of NF- $\kappa B$ in the nucleus. OPN levels correlated positively with NF- $\kappa B$ levels, which was highly consistent with the western blotting results.

The results of this study showed that in osteoblasts transfected with Over-OPN, the NF$\kappa \mathrm{B}$ subunit $\mathrm{P} 65$ was strongly expressed in the nucleus, whereas when they were transfected with OPN-siRNA, nuclear NF- $\mathrm{B}$ P65 was present at low levels. Therefore, we suggest that OPN accelerates the nuclear translocation of NF- $\kappa B$ via different upstream pathways. This translocation of NF- $\kappa B$ is also a necessary condition for the regulatory role of the NF- $\kappa B$ pathway. The protein levels of NF-kB P65 and p-P65 were also determined. When OPN was significantly upregulated, p-P65 levels were higher than P65 levels, which may be related to the modification of the protein. Over-OPN upregulated the expression of cathepsin $\mathrm{K}$ and MMP9, whereas OPN-siRNA downregulated their expression. In osteoblasts transfected with Over-OPN, the expression of NF- $\mathrm{B}$ P65 tended to be the same as in osteoclasts. OPN had a positive effect on RANKL expression, whereas the expression of OPG negatively affected RANKL expression, which further explained the inhibitory effect of OPN on OPG (Fig. 7C).

\section{Discussion}

A periapical lesion is caused by bacteria in the periapical tissue, and is accompanied by local bone resorption [11]. LPS is a pathogenic component of Gram-negative bacteria that induces a series of inflammatory reactions. It is also one of the main causes of bone resorption [12]. LPS induces osteoclast formation through the RANKL pathway to support osteoclast survival and fusion. LPS also stimulates the secretion of tumor necrosis factor $\alpha(\mathrm{TNF}-\alpha)$ and induces cell transformation into osteoclasts $[13,14]$. Several studies have shown that LPS also directly induces osteoblast necrosis and apoptosis. In a study of fracture healing in an animal model, the injection of LPS delayed the healing of fractures and reduced the strength of the new bone [15-17].

OPN is a secreted phosphorylated glycoprotein that was first discovered in bone tissue [18, 19]. The primary protein structure of OPN contains the highly conserved arginine-glycineaspartate (RGD) sequence, which is involved in cell chemotaxis and adhesion [6, 20]. OPN participates in a variety of metabolic processes, including bone metabolism, tumor growth, and metastasis. It contains seven exons and six introns, and is encoded on chromosome 4. In the bone, OPN is secreted by osteoblasts, osteoclasts, and bone cells, and plays a very important role in bone resorption [21-25]. In healthy bones, OPN is located at sites of new bone formation. Importantly, its RGD sequence allows it to mediate osteoblast and osteoclast adhesion [26-28]. Therefore, we hypothesize that OPN is expressed in chronic periapical lesions. In this study, we investigated whether OPN is chronically expressed and analyzed the relationship between OPN and other inflammatory factors in chronically affected human tissues. The expression of OPN, NF- $\mathrm{KB}, \mathrm{MMP9}$, and cathepsin $\mathrm{K}$ was significantly higher in tissues affected with periapical lesions than in the control tissues, perhaps because OPN plays a role in maintaining the normal physiological metabolic activity of apical tissues. After the cells were stimulated by external factors, the activity of OPN changed, and it played a 


\section{Cellular Physiology Cell Physiol Biochem 2018:49:884-898 $\begin{array}{ll}\text { DOI: 10.1159/000493219 } & \text { O } 2018 \text { The Author(s). Published by S. Karger AG, Basel } \\ \text { and Biochemistry } & \text { Published online: } 5 \text { September, } 2018 \text { www.karger.com/cpb }\end{array}$ \\ Dong et al.: Osteopontin Promotes Bone Destruction in Periapical Periodontitis}

role in bone destruction in the periapical tissues. A correlation analysis showed that OPN correlated with NF-KB and cathepsin K, but not with MMP9. This indicated that other pathways are involved in the release of MMP9 during the process of the chronic diseases caused by many bacteria. To verify the mechanism of OPN action in periapical lesions, we first used immunohistochemistry and real-time PCR to determine the expression of OPN in mice. Our results showed that OPN is expressed throughout development. OPN expression and osteoclast numbers showed the same trends from week 1 to week 4 of infection, and correlated positively, suggesting that under pathological conditions, inflammatory factors activate the differentiation of osteoclasts and inhibit that of osteoblasts, leading to bone destruction and dissolution.

In this study, we confirmed that LPS directly promotes the differentiation and proliferation of osteoclasts but inhibits the differentiation and proliferation of osteoblasts. OPN increases the expression of TRAP, cathepsin K, and MMP9, which play important roles in regulating osteoclast differentiation and bone desorption. OPN enhances the movement and aggregation of osteoclasts and promotes the adhesion of osteoclasts to the bone matrix. Several studies have confirmed that OPN interacts with integrin $\alpha \mathrm{v} \beta 5$ to regulate osteoclast activity and induces TRAP to degrade the bone matrix $[29,30]$. Others studies have shown that OPN stimulates CD44 expression and that CD44 increases the activity of osteoclasts and promotes bone desorption. When the Opn gene was knocked out in mice, the expression of CD44 in their osteoclasts was significantly reduced [31, 32]. In the process of bone remodeling, osteoblasts produce the OPN stored in the bone matrix [9, 30, 33]. When the bone is absorbed, OPN is released from the bone matrix and adheres to osteoblasts. Therefore, OPN is generally considered to promote bone mineralization [24-26, 34]. However, Huang reported that OPN inhibited the proliferation and differentiation of osteoblasts in vitro, and that the overexpression of OPN inhibited mineral deposition in bone tissue [21]. Our results confirmed that OPN inhibits osteoblast proliferation and differentiation and promotes osteoclast proliferation and differentiation.

RANKL has a strong capacity to induce osteoclast activity. RANKL has two ligands, RANK and OPG $[1,17]$. In this study, we showed that the NF- $\kappa B$ pathway regulates the binding of RANKL to RANK to promote osteoclast differentiation and the activation of bone damage $[13,35,36]$. This process also involves the binding of OPG to RANKL, which, on the one hand, reduces the chance of RANK binding RANKL, and on the other hand, inhibits osteoclast differentiation, regulates bone reconstruction, improves bone density, and maintains bone homeostasis [34, 37].

\section{Conclusion}

OPN activates the NF- $\kappa B$ pathway and accelerates the transfer and phosphorylation of p-NF- $\kappa$ B P65 from the cytoplasm to the nucleus. In the nucleus, p-NF- $\mathrm{BB}$ P65 regulates the transcription of genes encoding bone transcription factors, affecting osteogenesis and osteoclast synthesis and the secretion of bone-damaging factors, and ultimately leading to bone destruction. How OPN activates the NF- $\kappa B$ pathway, which may involve pathways not investigated here, will be the future direction of our research into the regulatory mechanisms of OPN.

\section{Acknowledgements}

This work was supported by National Natural Scientific Grants (No.31570798), China and Liaoning Province National Natural Science foundation (201602233) and by the program for professor of special appointment in Liaoning province, Liaoning Excellent Talents in University (LR2017042) and by the program for Liaoning Provincial Program for Top Discipline of Basic Medical Sciences.

\section{Disclosure Statement}

The authors declare no conflict of interests. 


\section{Cellular Physiology Cell Physiol Biochem 2018;49:884-898 and Biochemistry DOI: 10.1159/000493219 2019 (O) 2018 The Author(s). Published by S. Karger AG, Basel

\section{References}

1 Kawashima N, Suzuki N, Yang G, Ohi C, Okuhara S, Nakano-Kawanishi H, Suda H: Kinetics of RANKL, RANK and OPG expressions in experimentally induced rat periapical lesions. Oral Surg Oral Med Oral Pathol Oral Radiol Endod 2007;103:707-711.

- Hosokawa Y, Hosokawa I, Ozaki K, Matsuo T: IL-27 modulates chemokine production in TNF- $\alpha$-Stimulated human oral epithelial cells. Cell Physiol Biochem 2017;43:1198-1206.

- 3 Hosokawa Y, Hosokawa I, Shindo S, Ozaki K, Matsuo T: IL-4 modulates CCL11 and CCL20 productions from IL-1 $\beta$-Stimulated human periodontal ligament cells. Cell Physiol Biochem 2016;38:153-159.

4 Imai H, Fujita T, Kajiya M, Ouhara K, Yoshimoto T, Matsuda S, Takeda K, Kurihara H: Mobilization of TLR4 Into Lipid Rafts by Aggregatibacter Actinomycetemcomitans in Gingival Epithelial Cells. Cell Physiol Biochem 2016;39:1777-1786.

5 Undale A, Srinivasan B, Drake M, McCready L, Atkinson E, Peterson J, Riggs BL, Amin S, Modder UI, Khosla S: Circulating osteogenic cells: Characterization and relationship to rates of bone loss in postmenopausal women. Bone2010;47:83-92.

6 Oh Y, Oh I, Morimoto J, Uede T, Morimoto A: Osteopontin has a crucial role in Osteoclast-Like multinucleated giant cell formation. J Cell Biohem 2014;3:585-595.

7 Xu ST, Zou FZ, Cai LN, Xu WL: The downregulation of OPN inhibits proliferation and migration and regulate activation of Erk1/2 in ECA-109 cells. Int J Clin Exp Med 2015;4:5361-5369.

-8 Tao X, Juxiang C, Yicheng L, Jinxu Z: Lentiviral-mediated siRNA against osteopotin in U251 glioma cell line. J Med Colleges PLA 2010:1-10.

-9 Cobo T, Viloria CG, Solares L, Fontanil T, Gonzálezchamorro E: Role of periostin in adhesion and migration of bone remodeling cells. Plos One 2016;1:e147837.

10 Zhang X, Liu F, Zhu G, Wang Z: Recombinant osteopontin attenuates hyperoxia-induced acute lung injury through inhibiting nuclear factor kappa B and matrix metalloproteinases 2 and 9. Chin Med J (Engl) 2014;127:4025-4030.

11 Maeda H, Wada N, Nakamuta H, Akamine A: Human periapical granulation tissue contains osteogenic cells. Cell Tissue Res 2004;2:203-208.

12 Sun Z, Wang L, Peng B: Kinetics of glycogen synthase kinase (GSK)3 $\beta$ and phosphorylated GSK3 $\beta$ (Ser 9) expression in experimentally induced periapical lesions. Int Endod J 2014;47:1107-1116.

13 Joung YH, Darvin P, Kang DY, Sp N, Byun HJ, Lee CH, Lee HK, Yang YM: Methylsulfonylmethane inhibits RANKL-Induced osteoclastogenesis in BMMs by suppressing NF-kappaB and STAT3 activities. Plos One 2016;11:e159891.

14 Kaomongkolgit R, Manokawinchoke J, Sanchavanakit N, Pavasant P, Sumrejkanchanakij P: Fibronectin supports TNF-alpha-induced osteopontin expression through beta1 integrin and ERK in HN-22 cells. Arch Oral Biol 2010;55:101-107.

15 Singh R, Hui T, Matsui A, Allahem Z, Johnston CD, Ruiz-Torruella M, Rittling SR: Modulation of infectionmediated migration of neutrophils and CXCR2 trafficking by osteopontin. Immunology 2017;150:74-86.

16 Andisheh-Tadbir A, Mardani M, Pourshahidi S, Nezarati K, Bahadori P: Prognostic value of matrix metalloproteinase- 9 expression in oral squamous cell carcinoma and its association with angiogenesis. J Clin Exp Dent. 2016;2:130-135.

17 Rittling SR, Craig Z, Kader Y, Stephen S, Noriyuki S: Protective role of osteopontin in endodontic infection. Immunology 2010;1:105-114.

18 Chen J, Singh K, Mukherjee BB, Sodek J: Developmental expression of osteopontin (OPN) mRNA in rat tissues: Evidence for a role for OPN in bone formation and resorption. Matrix 1993;13:113-123.

-19 McKee MD, Nanci A: Osteopontin at mineralized tissue interfaces in bone, teeth, and osseointegrated implants: Ultrastructural distribution and implications for mineralized tissue formation, turnover, and repair. Microsc Res Techniq 1996;33:141-164.

20 Zhu F, Shen F, Fan Y, Xie Y,Xia Y, Kong Y: Osteopontin increases the expression of beta1, 4-galactosyltransferase-I and promotes adhesion in human RL95-2 cells. Glycoconj J 2012;29:347-356. 


\section{Cellular Physiology Cell Physiol Biochem 2018;49:884-898

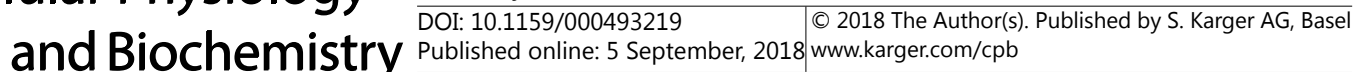

21 Huang W, Carlsen B, Rudkin G, Berry M: Osteopontin is a negative regulator of proliferation and differentiation in MC3T3-E1 pre-osteoblastic cells. Bone 2004;5:799-808.

22 Walker CG, Dangaria S, Ito Y, Luan X, Diekwisch TGH: Osteopontin is required for unloading-induced osteoclast recruitment and modulation of RANKL expression during tooth drift-associated bone remodeling, but not for super-eruption. Bone 2010;47:1020-1029.

-23 Holm E, Gleberzon JS, Liao Y, S Rensen ES, Beier F, Hunter GK, Goldberg HA: Osteopontin mediates mineralization and not osteogenic cell development in vitro. Biochem J 2014;464:355.

-24 Ono N, Nakashima K, Rittling SR, Schipani E, Hayata T: Osteopontin negatively regulates parathyroid hormone receptor signaling in osteoblasts. J Biol Chem 2008;28:19400-19409.

25 Su CM, Chiang YC, Huang CY, Hsu CJ, Fong YC, Tang CH: Osteopontin promotes oncostatin m production in human osteoblasts: Implication of rheumatoid arthritis therapy. J Immunol 2015;195:3355-3364.

26 N T, BD W, J K, HH C, RP S, SM S, HA G, Dixon S: Osteopontin signals through calcium and nuclear factor of activated t cells (NFAT) in osteoclasts. J Biol Chem 2011;46:39871-39881.

27 Pietras A, Katz AM, Ekstrom EJ, Wee B, Halliday JJ, Pitter KL, Werbeck JL, Amankulor NM, Huse JT, Holland EC: Osteopontin-CD44 signaling in the glioma perivascular niche enhances cancer stem cell phenotypes and promotes aggressive tumor growth. Cell Stem Cell 2014;14:357-369.

28 Zuo C, Huang Y, Bajis R, Sahih M, Li YP: Osteoblastogenesis regulation signals in bone remodeling. Osteoporos Int 2012:1653-1663.

29 YJ K, K F, J C, Aplin J: The role of the osteopontin-integrin avb3 interaction at implantation: Functional analysis using three different in vitro models. Hum Reprod 2014;4:739-749.

-30 Inman CK, Shore P: The osteoblast transcription factor Runx2 is expressed in mammary epithelial cells and mediates osteopontin expression. J Biol Chem 2003;49:48684-48689.

-31 Wu YX, Wu TY, Xu BB, Xu XY, Chen HG: Protocatechuic acid inhibits osteoclast differentiation and stimulates apoptosis in mature osteoclasts. Biomed Pharmacother 2016:399-405.

-32 Hans S, Mali AM: Estimation and comparison of osteopontin levels in plasma in subjects with healthy periodontium and generalized chronic periodontitis and its assessment after scaling and root planing. J Indian Soc Periodontol 2012;3:354-357.

-33 Yamaguchi M, Vikulina T, Arbiser JL, Weitzmann MN: Suppression of NF-kB activation by gentian violet promotes osteoblastogenesis and suppresses osteoclastogenesis. Curr Mol Med 2014;6:783-792.

-34 Liu J, Liu Q, Wan Y, Zhao Z, Yu H: Osteopontin promotes the progression of gastric cancer through the NF- $\mathrm{KB}$ pathway regulated by the MAPK and PI3K. Int J Oncol 2014:282-290.

-35 Guo H, Mi Z, Bowles DE, D S, Bhattacharya, C KP: Osteopontin and protein kinase c regulate PDLIM2 activation and STAT1 ubiquitination in LPS-treated murine macrophages. J Biol Chem 2010;48:37787-37796.

-36 Zhao W, Wang L, Zhang M, Wang P, Zhang L: NF-KB- and AP-1-mediated DNA looping regulates osteopontin transcription in Endotoxin-Stimulated murine macrophages. J Immunol 2011;5:3173-3179.

-37 Hunter GK: Role of osteopontin in modulation of hydroxyapatite formation. Calcif Tissue Int 2013;4:348354. 